\title{
RECONSIDERING POSTGRADUATE "SUPERVISION" FROM A PARTICIPATORY ACTION LEARNING AND ACTION RESEARCH APPROACH
}

\author{
L. Wood \\ COMBER \\ Faculty of Education \\ North-West University \\ Potchefstroom, South Africa \\ e-mail: lesley.wood@nwu.ac.za
}

\section{Louw}

Faculty of Natural and Agricultural Sciences

University of Pretoria

Pretoria, South Africa

e-mail: ina.louw@up.ac.za

\section{ABSTRACT}

Postgraduate supervision is most often perceived as a one-to-one relationship between an expert and a novice researcher. Even when working in groups, an instructional approach tends to dominate, where the supervisor(s) prescribe(s) the content and process, with a narrow focus on the outcome of degree completion, rather than a more holistic approach to the development of postgraduate scholars. At a time when curriculum transformation is high on the agenda of Higher Education, we problematise this traditional conceptualisation of postgraduate supervision and argue for a more participatory action learning and action research (PALAR) approach to postgraduate learning and development. PALAR creates a relational and reflective space for dialogical conversations, equalizing traditional power relations and democratising knowledge creation. This opens up the possibility for postgraduate candidates to perceive themselves as self-directed lifelong learners and collaborative action leaders, rather than just "students". Using a case example of a postgraduate PALAR retreat, we thematically analyse the data generated from participant reflections, presented over three days in visual, oral and other creative forms. Findings reveal that this approach to postgraduate learning and development enhances critical thinking and promotes collaboration rather than competition. Participants are thus able to see themselves as developing scholars and action leaders within their specific fields of influence. Such outcomes are likely to provide a solid foundation for developing future academics or other professionals, able to model a holistic, participatory approach to knowledge creation in their own practice.

Keywords: action leadership, transformation, dialogic thinking, higher education, post graduate students 


\section{INTRODUCTION}

Supervision is defined as "the action or process of watching and directing what someone does or how something is done” (http://www.merriam-webster.com/dictionary/ supervision). Based on international literature (Chiappetta-Swanson and Watt 2011; Whisker et al. 2013), the supervisory experience still tends to be defined as a one-to-one relationship between an "expert" in a specific discipline who "directs" a student to complete a thesis that meets specific academic and disciplinary requirements. In this era of performativity in Higher Education (Leathwood and Read 2013), the focus in supervision is often on "getting students through" in the minimum time, rather than embracing it as an opportunity to develop the students as emerging professionals with the capacity to be critical, yet collaborative; confident in their own opinion, yet open to critique; and able to appreciate the value of working in a participatory and reflective way within a diverse group to ensure that they remain lifelong learners - all skills needed for leaders within the modern workplace. In this article we build on the existing literature that positions postgraduate study as a relational and empowering process (e.g. Bak 2011; Fataar 2005; Grant 2010; Hugo 2009; Waghid 2015) by presenting a case study that illustrates these principles in practice. Although we do not position our approach as the "best" method, we think it offers a good example of how to counter the danger of supervision becoming merely a means to an end (another output for the university); a once-off experience that is often found to be painful rather than pleasant, for both student and supervisor. Petersen (2007) warns of the danger of the uncritical assessment of supervision as "effective" if the degree is awarded within the required time. The illustrative case offered in this article provides an alternative, participatory and democratic approach to postgraduate supervision practices that helps students develop the required epistemic imperative for postgraduate studies (Hugo 2009); the relational and dialogical skills (Fataar 2005; Waghid 2015) to respect the humanity of the other (Bak 2011); and encourages students to develop their own voices and autonomy (Fataar 2013; Grant 2010), learning not only from and with the allotted supervisor, but also from each other.

Since the supervisory experience and particularly the relationships formed therein is the most powerful influence on the development of an identity as a scholar (Löfström and Pyhältö 2012), we argue that we have to go beyond merely following predetermined steps for "effective" supervision and begin to think about how we might develop lifelong learners who continually strive to improve their practice in whatever field they operate; who can listen to and learn from others who may have different views from their own; and who can form relationships that promote deep critical reflection on self and others' learning. In short, to enable them to develop skills that will benefit them throughout their professional and personal lives and not only equip them in the field of scholarship. 
We therefore oppose the idea of "supervision", based on traditional hierarchic power relations, preferring instead to talk about the professional learning and development of postgraduate students, that goes deeper than the "frivolous conceptions of learning" (Waghid 2006, 247) that they may have on enrolment for the degree. This is not a new idea - others have written extensively about the supervisory relationship as a site for identity formation (see Green 2005; Petersen 2007), where learning is not only about learning to do, but also learning to be a professional, whether employed in higher education or outside. However, our contribution to the debate is to provide empirical evidence of how a participatory action learning and action research (PALAR) paradigm for guiding postgraduate learning creates the relational and reflective space for the critical and dialogical conversations vital to the supervision process (Fataar 2013; Waghid 2015), helping to equalize traditional power relations and democratize knowledge creation through reflexive dialogue between a group of students and their supervisors. Although several writers have proposed a group approach to supervision (see Choy, Delahaye and Saggers 2015; De Lange, Pillay and Chikoko 2011), recognizing the importance of creating a collaborative learning experience, the agenda for such groups still tends to be determined and delivered by "experts" (established researchers) according to a specific timeline where all members of such groups tend to be at the same stage of study. There are also many debates about whether supervision should be viewed more as a pedagogical activity, rather than a research one (Wilkinson 2011), but such binaries do not concern us, as we regard all scholarship as integrated (Zuber-Skerritt, Wood and Louw 2015). Instead, we explain in this article how a PALAR approach to postgraduate learning and development allows students to take more control over deciding what they need to learn, to critique what they are being taught, to access support when needed, and to work with their peers to co-construct knowledge that they deem to be relevant, all vital skills to develop, whether as professionals or lay citizens, so as to be able to live and work in a rapidly changing and diversifying world. We believe a PALAR approach allows us to enable students to develop the "capacities to imagine alternative possibilities" and to establish relational spaces "whereby meanings could be shared, understood, reflected on and contested” (Waghid 2006, 433).

We thus offer what Lee (2007) points out is lacking in the field - a conceptual framework for postgraduate development that: i) democratizes the process of knowledge creation by acknowledging what the student brings to the learning; ii) problematizes the positioning of the supervisor as “director” of the postgraduate project; iii) encourages critical thinking about how, why, when and where we should and can learn; and iv) generates knowledge that can be used to improve everyday living and working, rather than only for academic purposes. Like Vaill (1996, 42), we agree that "learning must be a way of being - an ongoing set of attitudes and 
actions by individuals and groups that they employ to try to keep abreast of the surprising, novel, messy, obtrusive, recurring events ...”.

Guided by the central research question, "How does a PALAR approach to postgraduate learning and development influence the development of self-directed, critical, democratic and lifelong learning?”, we first explain the theoretical foundation of such an approach, before outlining the methodology we adopted to produce empirical evidence of participant learning and development. We then present a discussion of this evidence to support the argument for a more participatory, democratic and transformative approach to postgraduate learning and development. Since postgraduate supervision the world over tends to differ only slightly, the findings from this article should be useful to inform postgraduate scholarship at universities in many countries.

\section{THEORETICAL FRAMEWORK}

We agree with Brew (2001), who conceptualizes postgraduate supervision as a personal journey of discovery, leading to transformation and the creation of a strong personal identity as a researcher and professional. The role of the "supervisor" then becomes more that of a mentor who creates a supportive, yet challenging space for this to happen. Capability theory offers a useful lens through which to understand such development.

Loots, Ts'ephe and Walker (2016) explain that the capability approach to human development, based on the work of Sen (1999), allows individuals to decide which freedoms or capabilities they need to reach outcomes that they consider to be valuable for improving their quality of life. We believe that the more traditional forms of supervision seldom allow emerging researchers to choose what and how they learn, since they are directed by their supervisor (individual supervision) or a prescribed programme (group supervision). A capability lens for doctoral learning and development would create space for the stimulation of reasoning, imagination and critical thinking (Waghid 2006; Nussbaum 2011) to promote learning and development beyond the postgraduate degree towards fostering both the personal and citizenship interests of the individual (Boni and Walker 2013). Walker (2010, 29) regards doctoral education as a "process of human development", aimed at securing the postgraduate student "the freedom to exercise genuine choices (capabilities), and to participate in equal decision making” about the process. Such choices are, of course, constrained by historical, social and structural factors, specifically in the case of a country like South Africa, where past economic, social and political inequalities and injustices still wield considerable influence over the access to and performance of students in higher education, including how they relate to their academic “superiors”. In addition, the prevailing neo-liberal discourse within higher education 
puts increased pressure on the academic to "produce” Ph.d.'s within a short time frame. There has been much written about the possible negative impact of this reality on the quality of student development (Brabazon 2016; Grealy and Laurie 2017; Maistry 2017). Walker (2007) has identified aspects that promote the formation of capabilities in students and resonate with the aims of a participatory action learning and action research (PALAR) approach - the development of voice; the enhancement of mutual dignity and respect for self and others; and the nurturing of critical thinking, independence and concern for others, particularly the marginalised. A PALAR approach to doctoral learning therefore aims to engender lifelong learning and development, for the ultimate purpose of promoting the social good for individuals, organizations and communities (Zuber-Skerritt 2015). PALAR strives to provide a humanizing space (Wood and Zuber-Skerritt 2013) for not only research support, but also the formation of relationships that provide much-needed emotional support over and above the thesis construction, since most doctoral candidates face many challenges in their "normal" lives, such as family responsibilities, demanding jobs, health issues and financial worries.

Therefore, both PALAR and the capabilities approach to doctoral education aim at developing holistic capabilities, rather than just research competences, that will enhance the learning of postgraduate students and their ability to continue to use this learning to lead others to develop similar capabilities. PALAR aims to enhance capabilities through: a focus on building relationships, critical reflection on learning and open recognition of each person's contribution. The process is based on an embodiment of democratic values and inclusive practices that support self-directed, lifelong learning, the valuing of others and the ability to live and work peacefully in diverse contexts (Zuber-Skerritt 2012). Zuber-Skerritt (2011) explains these core values as the advancement of knowledge through critical reflection; collaboration through symmetrical communication; trust through constructive and caring feedback; openness through the creation of new opportunities and experiences; and the development of contextually relevant theories through coaching, which become significant through the attainment of team results. The relationship focus shifts the doctoral journey from an individual, and generally more limited learning experience, into a participatory pathway towards a collaborative, caring ontology that will shape ways of working and living to better suit the demands of the ever-changing times in this twenty-first century. This claim is supported by Harri-Augstein and Thomas (2013), who used "learning conversations" in their organisational development work. Their learning process required participants to first selfreflect on a specific topic, before engaging in group dialogue, and then reflecting again on their own. Their research suggests that this iterative process of individual and group learning develops capacity for self-directed learning and the ability to adapt to ever-changing 
environments. This is precisely the process that PALAR follows through the constitution of action learning sets.

\section{METHODOLOGY}

This article presents our explanation of a three-day retreat as an exploratory case study (Yin 2013) to provide evidence of our claims to knowledge. This particular retreat took place in year four of a five-year research project, which aimed to create theory about how community engagement can be conducted by Faculties of Education through research and, specifically, postgraduate studies. Three of the ten Ph.D. candidates were in their first year of study and at proposal writing stage; one was about to start field work; while the six remaining candidates were on the last chapter of their thesis. They were predominantly female (7) and black (8). Only three of them were employed in academia; six were teachers and one a manager at a college of further education. All were using various forms of participatory action research and so were familiar with the paradigms and principles associated with it. They were all registered in the research project of the lead author. The other author and a guest facilitator were collaborators in the project and experienced in collaborative ways of learning; and all bar two newly enrolled candidates had participated in retreats with the facilitators before. In addition, a colleague who was also running a project using a PALAR design was invited to participate, to learn how to use such an approach with her students (C1). For the purpose of this case study, we employed a qualitative design to capture the lived experience of the participants (Merriam and Tisdell 2015).

Data were generated through transcriptions of reflective feedback sessions, written reflections of participants, video-recordings of presentations of learning, and the metareflections of the three facilitators. The data were thematically analysed (Creswell 2003) independently by two of the facilitators who then came to consensus, while the third validated the final themes. Ethical clearance had been gained for the umbrella project (NWU-00040-1442) and all participants signed consent forms for their data to be used for publication purposes.

\section{DISCUSSION OF FINDINGS}

Three main themes emerged from the data analysis, and these will be discussed below, integrated with an explanation of how the PALAR approach to postgraduate learning and development was applied. The discussion is supported by direct quotations from participants and by relevant literature. 


\section{Theme 1: The value of a safe, relational space}

All of the participants mentioned how much they valued the safe space that was created to build relationships. Although some of the participants had known each other for between two to four years, it was the first time for some of them to experience such a "humanising space” (P7). On the final day, they were split into three groups according to the stage of study they were at and asked to present their reflections on their learning in a creative way. One group did a mime and posters; another showed a video and discussed it; and another did a PowerPoint presentation; the colleague and the facilitators presented their learning through using photographs. The mime showed someone struggling to walk and others coming to help him. Only when he was helped to his feet could he speak - "I am feeling so much better now, I am glad you are here" (P2), portraying that the feeling of safety and belonging within the group gave them a voice, since they knew they were being listened to with respect. As P10 said, "There were a few debates where differences occurred, but all listened, decided for themselves what to change or do". Thus, it appears that their capacity to make choices (Walker 2010) was increased. The collaborative and critically reflective way of working allowed them to feel competent and begin to build confidence that their contribution to learning was just as important as that of more seasoned researchers:

"This group is like a family and I wish we could be together. I see values like knowledge, confidence, assertiveness, influence, compassion among us. Having well known researchers is good, it makes us confident to rub shoulders with high profile people. We are learning all the time and we cannot learn in vacuum - isolation is the enemy of improvement. The group has opened my eyes and uplifted me, I leave here knowing I have the support of the group.” (P5).

Such feelings were created through the facilitators and the longer-term participants modeling symmetrical communication, where everyone's input and work was considered to be a contribution, rather than the facilitators being considered the experts (Zuber-Skerritt 2011). Humour was used to create a relaxed atmosphere, which enabled everyone to be able to laugh at themselves: "I had the wrong idea about my methodology, but now I can laugh at it" (P2). As P1 said: "It was fun to learn with each other and the coaches”, while P9 indicated that humour was a strong learning tool that is needed when working with complex issues - it enriches the process without trivializing the issue.

We also fostered relationships by beginning each day with different relationship building exercises that required participants to communicate on a deeper, personal level so that they could see each other as people, struggling with similar life and study issues, rather than just as fellow students. This allowed commonalities to emerge across a fairly diverse group and helped 
them to feel safe to communicate their feelings and needs. They seemed to value the caring relationship that prevailed, the "friendship" (Waghid 2006, 428) that developed not only between them and the supervisors, but among themselves. As P6 said, "The exercise in the garden helped us to meet each other in a non-judgmental way ... felt liberated - could express openly and freely. We saw that we are trying to change, help, improve, care for others. This caused me great excitement.”

As coaches, we used a Socratic approach (Zuber-Skerritt, Wood and Louw 2015) asking questions rather than prescribing answers, which allowed the participants to open up to us also ("When you ask for help, you get direction, - not prescriptive, just an indication of direction" (C)). P1 summed up how the participants felt about the group interaction: "I don't have to pretend, can differ, be myself and move forward together. Our studies all connect in some way - we create a strong system.”

The findings confirm that relationship is central to postgraduate learning and development (Fataar 2013; Grant 2010; Waghid 2006). Learning is a social, emotional and cognitive experience (Fletcher 2015), but cognitive development cannot occur until people feel safe, valued and appreciated by those who are facilitating their learning.

\section{Theme 2: Creating a caring, yet challenging climate for learning}

The goal of each participant was, of course, to attain a Ph.D. degree, and so, as Hugo (2009) stressed, building relationships was not sufficient to promote the degree of criticality needed at doctoral level. We aimed to create a climate conducive to learning, but also to push participants out of their comfort zones by requiring them to present their work both to the whole group and in smaller groups. Critical thinking was enhanced by engaging them in critique of each other's presentations, while at the same time being mindful of the need to deliver critique in a kind and constructive way. The three participants who were at proposal stage were very nervous about presenting their work, so one of the facilitators (their supervisor, whom they knew well) offered to listen to them and invited anyone else who wished to come, to do likewise. Four other participants attended and the whole exercise turned out to be a valuable learning experience for them, as their peers engaged critically with their work and gave valuable input, which helped them to clarify their questions and design.

Group critique made them "eager to work” (P3); it "confirmed that the way I was thinking is ok” (P2); helped them to see the value of having "critical friends” (P1); and taught them how to give and receive critique. As P5 said, "Learning leads to the power of knowledge and that power leads to increased confidence, which in turn allows you to share your knowledge with others and have assertiveness. You become open to influence people and still be 
compassionate.”

“The opportunity to interact and speak to others pushed me out of boundaries ... way in which it was done was a 'I want to help you' attitude which allowed you to say what you mean - I learnt from others also, we helped each other” (P9). Even when "errors” were pointed out, it was perceived as helpful critique. Participant 10 said he had a "traumatic experience - a vital piece (of my study) was missing, it was good trauma, the group helped me to work through it” (P10).

It is clear that the peer interaction helped to develop their ability to critically consider their own learning, as they listened, reflected and considered what changes to make - in other words, the action learning process enabled them to engage in cycles of reflection and action, leading to improvement in their central argument and how they attempted to research it.

We had organized a Skype session with a colleague in Australia, who gave some input on critical thinking and then the participants watched a short video, chosen to make them question many of their assumptions, which it succeeded in doing, as the subsequent discussion revealed. This session was perceived as being very helpful in assisting them to see issues from various angles. One of the group reflective presentations focused on how they had shifted from linear thinking to an appreciation of complexity thinking. As Participant 6 stated: "The only predictability about this retreat is that we have to ask questions and we will be asked questions - and supported to find answers if needed. Our expectations have been disrupted.”

Thus, critical thinking was enhanced, but the participants also learnt the importance of delivering critique as a means to help each other learn - rather than to bring each other down, as is often the case in academic and workplace contexts.

\section{Theme 3: Creating opportunity for becoming lifelong, self-directed learners}

PALAR involves creating action learning sets, or dialogical spaces, where all learn from each other (Zuber-Skerritt, Wood and Louw 2015). The dialectical process of knowledge generation involves the articulation of knowledge, sharing thereof, modifying of ideas and the internalisation of transformed information (Schulman 1999). We wanted participants to appreciate the value of such dialectical spaces for lifelong learning and development, so we were gratified to note the remark of one student in her final reflection: "I am not worried about the title of Dr, I just want to learn” (P5).

Apart from a plenary reflective session at the start and end of each day, participants could choose to work in groups or individually with a specific coach; or to form groups on their own; or work individually. This way, we encouraged interaction, but also gave them the choice of how, what and from whom to learn. They could thus have the freedom to decide what was 
valuable for them (Walker 2010). For example, this approach helped P5 to feel "validated, appreciated. I can explain to others who did not know what I was doing - I was listened to. My ideas were validated and this helped me to clear them up.” They also appreciated the fact that as coaches, we had different areas of expertise (writing, methodology, technical issues etc.) and different inputs, so they could choose with whom to interact and when according to the support they needed.

They realised that this approach was helping them to prepare for the workplace, since they will have to work collaboratively in future, without a supervisor or mentor to guide them (e.g. "I know how to ask for help now and in the future, and that all learning must lead to action" (P3). They also learnt to compromise, an important skill for future interaction, since the presentations catered for different preferences - the more extrovert members of the group took on more upfront roles, while the others were able to provide input in a way that they preferred, but they all collaborated to get their messages across.

One of the participants offered to do a relationship building exercise, which did not turn out to be very successful, but the group gave her such good critical feedback that she felt empowered rather than deflated by the experience. The skill of giving and receiving constructive critique is a vital one for creating positive relationships in an increasingly diverse world. As was pointed out in one presentation, the diversity in the group made it stronger; the participant now felt that she had become "wiser”, but it was not her wisdom alone, it was wisdom emanating from the group. This participant summed her experience up in these words: "We came together here and from coming together I got supported and cared for: in the process I grew stronger and stronger and now I am ready to go!”(C). Boni and Walker (2016) highlight the link between participatory research and capability formation, as participation renders human development a democratic and power-sensitive process, embedded in relationships and a sense of affiliation to particular groups.

Another participant commented on the general lack of such collaborative spaces for learning within the academy: "an improved sense of community is needed in educational research ... it is more and more a space where we need to share ideas” (P9). Capability theory (Sen 1999) asserts that educational well-being is enhanced by creating space for the persons to feel good about their learning and development and to learn to value it as a lifelong asset. This stands in stark contrast to the past experiences of most of these participants, where critique was delivered "in a vacuum" (P7), which made it more of a soul-destroying, rather than a growthenhancing experience. 


\section{CONCLUDING REMARKS}

As supervisors, we also learnt much from reflecting on this experience. It confirmed for us the value of collaborative, critical reflection within caring dialogical spaces, founded on trusting relationships. We have worked with variations of this group over a few years, and so for most, learning had taken place over a long period, and not just at this retreat. However, since five of them were coming to the end of their Ph.D. journey, it was gratifying for us to see how they had matured in terms of becoming lifelong, critical learners who could work collaboratively and could model this to other less experienced participants. For the newer participants, this was a learning space they had not previously encountered at university - strange as it may seem, teacher education students do not learn about leadership and creating learning communities. We believe that this sort of experience should be the norm for postgraduate students, rather than the exception. Our reflection on the evidence presented here convinces us that such an approach helps to develop action leaders (Zuber-Skerritt 2011) who embody the leadership competences of collaboration and an ability to create a democratic and dialogic space for learning in which both relationships and critical, innovative thinking are fostered. Action leaders are able to articulate and self-reflect on their own thinking; are open to learning from others and able to critique in a caring way, while collaborating towards action to attain a common vision (ZuberSkerritt 2011). Figure 1 (constructed by the authors) gives an overview of how the characteristics of PALAR can be incorporated into postgraduate learning and development, based on our learning over the past few years.

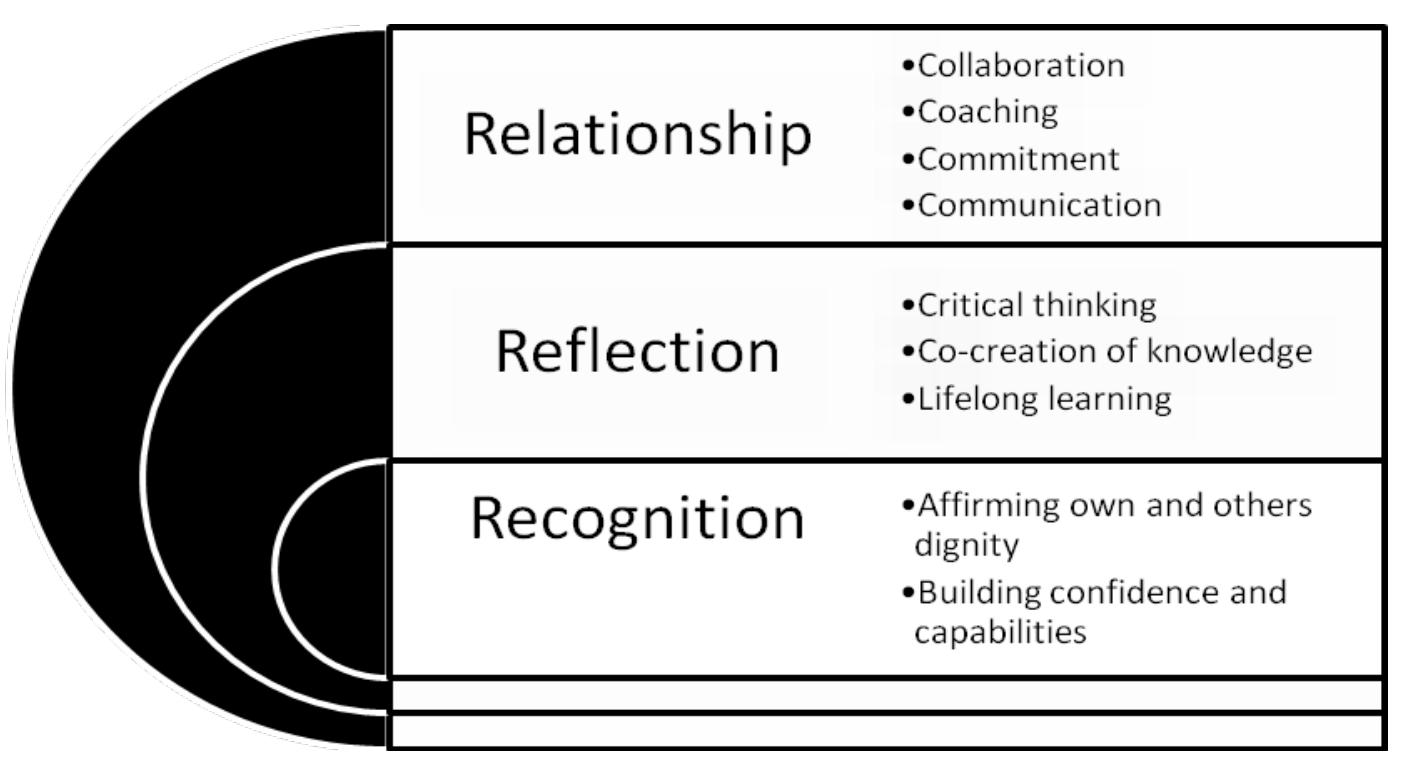

Figure 1: A PALAR approach to postgraduate learning and development.

The first and vital step is creating a democratic, caring relationship with and between postgraduate students and academic advisors. We do this, as explained above, through carefully 
chosen relationship building exercises, the use of humour, and modeling collaborative, democratic and synergistic communication, which enable us to be coaches of learning, rather than directing it. Although other scholars have underlined the importance of creating relationship spaces for supervision as indicated earlier in this article, the evidence provided here stresses the value of a participatory and collaborative group process, rather than exclusively one-on-on relationships. Reflection is promoted through experiential learning of critical thinking and opportunities to work with other postgraduate students, and not just the supervisor, to co-create knowledge. The ability to reflect on a level that fosters deep learning is not easy and we scaffold this through various experiential exercises within a safe and supportive climate. Finally, as this case study shows, we provide space for recognition of learning within a climate that affirms dignity, and thus increases confidence and willingness to become a lifelong learner. Public recognition of learning is one of the best motivators, yet it is often a missing factor during postgraduate studies, with opportunities to present to others only usually afforded on completion of the degree.

The findings presented here provide answers to our research question about how a PALAR approach to postgraduate learning and development can influence the development of selfdirected, critical, democratic and lifelong learning. They highlight how students learnt to make their own decisions about what they considered to be important learning for their purposes; critical thinking was developed through cycles of collaborative reflection and action; and they learnt to deliver critique in a way that promoted the learning and dignity of others. They felt valued and welcomed in the group. Participants also provided evidence that they were able to translate such learning to their everyday lives, thus choosing what knowledge was important for them and applying it in a relevant and contextualized way. They learnt how to model action leadership and will thus be in a better position to influence others within their personal and professional settings to be lifelong learners. We conclude that if more postgraduate students were exposed to a PALAR approach to learning and development, they would be able to learn vital skills that would enhance their capabilities not only for research, but also for life.

\section{ACKNOWLEDGEMENTS}

The authors would like to thank the postgraduate students who participated in this project. This work is based on research supported by the National Research Foundation. Any opinion, finding and conclusion or recommendation expressed in this material is that of the author(s) and the NRF does not accept any liability in this regard. 


\section{REFERENCES}

Bak, N. 2011. Professionalising the supervision relationship. A reply to Waghid, Fataar and Hugo. South African Journal of Higher Education 25(6): 1047-1061.

Brabazon, T. 2016. Winter is coming: Doctoral supervision in the neoliberal university. International Journal of Social Sciences \& Educational Studies 3(1): 14-34.

Brew, A. 2001. Conceptions of research: A phenomenographic study. Studies in Higher Education 26(3): 271-285.

Boni, A. and M. Walker. 2016. Universities and global human development: Theoretical and empirical insights for social change. Abingdon, UK: Routledge.

Boni, A. and M. Walker. 2013. Human development and capabilities: Re-imagining the university of the twenty-first century. Abingdon, UK: Routledge.

Chiappetta-Swanson, C. and S. Watt. 2011. Good practice in supervision and mentoring of postgraduate students: It takes an academy to raise a scholar. Hamilton, Ontario: McMaster University.

Choy, S., B. L. Delahay and B. Saggers. 2015. Developing learning cohorts for postgraduate research degrees. The Australian Educational Researcher 42(1): 19-34.

Creswell, J. W. 2003. Research design: Qualitative, quantitative and mixed methods approach. Thousand Oaks, CA: Sage Publications.

De Lange, N., G. Pillay, and V. Chikoko. 2011. Doctoral learning: A case for a cohort model of supervision and support. South African Journal of Education 31: 15-30.

Fataar, A. 2013. A pedagogy of supervision: "knowledgeability" through relational engagement. Journal of Education 58: 111-133.

Fataar, A. 2005. Negotiating student identity in the doctoral proposal development process: A personal reflection. Journal of Education 36: 37-58.

Fletcher, M. A. 2015. Professional learning. In Professional learning in higher education and communities: Towards a new vision for action research, ed. O. Zuber-Skerritt, M. A. Fletcher and J. Kearney, 41-75. London: Palgrave-Macmillan.

Grant, B. 2010. The limits of teaching and learning: indigenous students and doctoral supervision. Teaching in Higher Education 15 (5): 505-517.

Grealy, L. and Laurie, T., 2017. Higher degree research by numbers: beyond the critiques of neoliberalism. Higher Education Research \& Development 36(3): 458-471.

Green, B. 2005. Unfinished business: Subjectivity and supervision. Higher Education Research \& Development 24(2): 151-163.

Harri-Augstein, S. and L. F. Thomas. 2013. Learning conversations: The self-organised way to personal and organisational growth. London: Routledge.

Hugo, W. 2009. Spiralling reference: A case study of apprenticeship into an academic community of practice. South African Journal of Higher Education 23(4): 703-721.

Lee, A. M. 2007. Developing effective supervision: Concepts of research supervision. South African Journal of Higher Education 21(4): 680-693.

Leathwood, C. and B. Read. 2013. Research policy and academic performativity: Compliance, contestation and complicity. Studies in Higher Education 38(8): 1162-1174.

Löfström, E. and K. Pyhältö. 2012. The supervisory relationship as an arena for ethical problem solving. Education Research International. doi:10.1155/2012/961505.

Loots, S., L. Ts'ephe and M. Walker. 2016. Evaluating black women's participation, development and success in doctoral studies: A capabilities perspective. South African Journal for Higher Education 30(2): 110-128.

Maistry, S. M., 2017. Betwixt and between: Liminality and dissonance in developing threshold competences for research supervision in South Africa. South African Journal of Higher 
Education 31(1):119-134.

Merriam, S. B. and E. J. Tidsell. 2015. Qualitative research: A guide to design and implementation. Hoboken, New Jersey: John Wiley \& Sons.

Nussbaum, M. 2011. Creating capabilities: The human development approach. Cambridge, MA: Belknap Press.

Petersen, E. B. 2007. Negotiating academicity: Postgraduate research supervision as category boundary work. Studies in Higher Education 32(4): 475-487.

Sen, A. K. 1999. Development as freedom. New York: Anchor Books.

Schulman, L. S. 1999. Taking learning seriously. Change July/August: 31-44.

Vaill, P. B. 1996. Learning as a way of being. San Francisco: Jossey-Bass Inc.

Waghid, Y. 2015. Are doctoral studies in South African higher education being put at risk? Leading article. South African Journal of Higher Education 29(5): 1-7.

Waghid, Y. 2006. Reclaiming freedom and friendship through postgraduate student supervision. Teaching in Higher Education 11(4): 427-439.

Walker, M. 2010. Doctoral education as capability formation. In The Routledge doctoral supervisor's companion: Supporting effective research in education and the social sciences, ed. M. Walker and P. Thomson, 29-37. London: Routledge.

Walker, M. 2007. Selecting capabilities for gender equality in education. In Amartya Sen's capability approach and social justice in education, ed. M. Walker and E. Unterhalter, 177-195. New York: Palgrave McMillan.

Whisker, G., K. Exley, M. Antoniou and P. Ridley. 2013. Working one-to-one with students: Supervising, coaching, mentoring, and personal tutoring. Abingdon, UK: Routledge.

Wilkinson, A. 2011. Postgraduate supervision as an advanced teaching and learning practice: Exploring the scholarship link. South African Journal of Higher Education 25(5): 902-920.

Wood, L. and O. Zuber-Skerritt. 2013. PALAR as a methodology for community engagement by faculties of education. South African Journal of Education 33(4): 1-15.

Yin, R. K. 2013. Case study research. Design and methods. Thousand Oaks, CA: Sage publications.

Zuber-Skerritt, O. 2015. Conceptual framework. In Professional learning in higher education and communities: Towards a new vision of action research, ed. O. Zuber-Skerritt, M. A. Fletcher and J. Kearney, 1-37. London: Palgrave McMillan.

Zuber-Skerritt, O. 2012. Introduction. In Action research for sustainable development in a turbulent world, ed. O. Zuber-Skerritt, 3-28. Bingley, UK: Emerald Books.

Zuber-Skerritt, O. 2011. Action leadership: Towards a participatory paradigm. Dordrecht: Springer.

Zuber-Skerritt, O., L. Wood and I. Louw. 2015. A participatory paradigm for an engaged scholarship in higher education: Action leadership from a South African perspective. Rotterdam: Sense Publishers. 